\title{
UPAYA PENINGKATAN SIFAT FARMASETIKA EKSIPIEN SEDIAAN TABLET DARI PATI UBI JALAR
}

\author{
Lamia Diang Mahalia
}

\author{
Program Studi Diploma III Gizi, Jurusan Gizi, Poltekkes Kemenkes Palangka Raya
}

\begin{abstract}
ABSTRAK
Abstrak :Indonesia merupakan salah satu penghasil pati dari umbi-umbian terbesar di dunia,namun masih impor $100 \%$ pati termodifikasi dari berbagai negara. Ubi jalar memiliki potensi sebagai bahan baku pembuatan eksipien tablet, namun masih membutuhkan proses modifikasi secara fisik dan kimia untuk menghasilkan derivatnya yang memiliki karakteristik farmasetika yang lebih baik. Oleh karena itu, pada penelitian ini dilakukan pengembangan eksipien sediaan tablet dari pati ubi jalar (Ipomoea batatas Lamk.) yang dimodifikasi secara fisikokimia dalam rangka meningkatkan sifat farmasetikanya dan membandingkan hasilnya dengan amilum ubi jalar alami. Eksipien dibuat dengan 3 metode yaitu modifikasi pati ubi jalar dengan pemanasan/pengukusan secara langsung, modifikasi dengan pentanol-1, dan modifikasi dengan proses asetilasi asam asetat. Berdasarkan analisis dengan metode deskriptif-komparatif, diperoleh hasil bahwa pati yang dimodifikasi dengan pentanol-1 memiliki kekerasan yang lebih tinggi $(\bar{x}=2,55 \pm 0,34)$ dibandingkan dengan pati alami $(\bar{x}=1,00 \pm 0,08)$. Sedangkan untuk ukuran partikel, menunjukkan bahwa pati termodifikasi dengan asam asetat memiliki ukuran partikel lebih besar $(\bar{x}=15,20 \pm 1,79)$ dibandingkan dengan kedua pati termodifikasi lainnya. Pati alami mempunyai sifat alir yang lebih baik $(\mathrm{Cl}=18,9 \% \pm 1,52)$ dibandingkan dengan pati yang dimodifikasi. Dari hasil analisis dapat disimpulkan bahwa karakteristik pati ubi jalar termodifikasi lebih baik dari karakteristik pati alami.
\end{abstract}

Kata kunci: pati ubi jalar termodifikasi, pengembangan eksipien

\begin{abstract}
Abstract :Indonesia is one of the biggest producer of sweet potato starch in the world, but still import $100 \%$ modified starch from other country. Sweet potato has a potential utility as a raw material of tablet excipient, but still needs physical and chemical modifications to produce derivatives that have better pharmaceutical characteristic. Therefore, this research aimed to develop tablet dosage form from sweet potato starch (Ipomoea batatas Lamk.) that was modified using physicochemical process in order to improve the pharmaceutical characteristic and compared it with native starch. The excipient was made of three kind of modification methods. The method was modified with direct heating/steaming, modified with penthanol-1, and modified with acetylation of acetate acid process. Based on descriptivecomparative analysis method, it can show that sweet potato starch modified with penthanol1 had a higher hardness value $(\bar{x}=2.55 \pm 0.34)$ compared with native starch $(\bar{x}=1.00 \pm 0.08)$. Particle size distribution of modified starch with acetate acid ( $\bar{x}=15.20 \pm 1.79)$ was greater than the other modified starch. Native starch had a good flow properties $(\mathrm{Cl}=18,9 \% \pm 1,52)$ compared with modified starch. From this analysis result, it can be concluded that modified starch characteristic was better than native starch.
\end{abstract}

Key word: modified sweet potato starch, excipient development 


\section{PENDAHULUAN}

Modifikasi secara fisik dan kimia pati dari umbi-umbian lokal khususnya pati ubi jalar merupakan upaya derivatisasi dari pati aslinya menjadi berbagai produk turunannya yang memiliki karakteristik farmasetik yang lebih baik khususnya untuk bahan baku pembuatan tablet. Di berbagai negara di dunia seperti Thailand, China, Brazil, Afrika, dan Asia secara umum, upaya modifikasi pati tersebut menjadi primadona untuk menghasilkan berbagai derivatnya yang memiliki karakteristik beragam sesuai dengan fungsi penggunaannya di berbagai bidang. Hal yang menjadi keprihatinan bangsa ini adalah bahwa Indonesia sebagai penghasil pati dari umbi-umbian yang besar tetapi dalam fakta penggunaan bahan baku pembuatan tablet masih impor pati termodifikasi secara fisik dan kimia dari berbagai negara di dunia.

Telah dilakukan sebelumnya studi tentang potensi berbagai pati tropis dari umbi-umbian lokal Indonesia khususnya ubi jalar sebagai bahan baku pembuatan eksipien tablet ${ }^{[1]}$ dan studi tentang karakterisasi fisikomekanika pati ubi jalar untuk formulasi sediaan tablet ${ }^{[2]}$. Namun pati lokal tersebut masih membutuhkan proses modifikasi secara fisik dan kimia untuk menghasilkan derivatnya yang memiliki karakteristik farmasetika yang lebih baik dan spesifik khususnya untuk pembuatan tablet. Penelitian ini dilakukan dalam upaya pengembangan eksipien sediaan farmasi dari amilum/pati ubi jalar lokal termodifikasi secara fisikokimia untuk peningkatan sifat farmasetikanya.

\section{METODE PENELITIAN}

1. Proses pembuatan amilum ubi jalar dapat dilihat pada Gambar 1.

\begin{tabular}{|c|c|}
\hline \multicolumn{2}{|c|}{ Ubi jalar } \\
\hline $\begin{array}{l}- \\
- \\
- \\
-\end{array}$ & $\begin{array}{l}\text { Dikupas kulitnya, dicuci } \\
\text { sampai bersih } \\
\text { Digiling } \\
\text { Tambah aquadest, } \\
\text { diperas dengan kain putih } \\
\text { Diendapkan (untuk } \\
\text { diambil patinya) }\end{array}$ \\
\hline \multicolumn{2}{|c|}{ Endapan } \\
\hline- & $\begin{array}{l}\text { Disaring pada kertas } \\
\text { saring dengan corong } \\
\text { buchner untuk } \\
\text { memisahkan amilum dari } \\
\text { aquadest } \\
\text { Dikeringkan (di lemari } \\
\text { pengering) } \\
\text { Dihaluskan } \\
\text { Diayak }\end{array}$ \\
\hline lum u & \\
\hline
\end{tabular}

Gambar 1. Proses pembuatan amilum ubi jalar

2. Ubi jalar yang telah dibuat menjadi amilum kemudian dimodifikasi dengan cara berikut :

a. Modifikasi dengan pemanasan/ pengukusan secara langsung (alpha starch) 
b. Modifikasi dengan pentanol-1 (pemutusan ikatan amilosaamilopektin)

c. Modifikasi dengan proses asetilasi asam asetat (pati asetat).

3. Analisis sifat farmasetika secara fisikokimia amilum ubi jalar dikomparasikan dengan amilum standar Amprotab. Adapun analisis yang dilakukan adalah sebagai berikut :
a. Analisis organoleptis
b. Analisis kelarutan
c. Identifikasi iodium
d. Analisis ukuran partikel
e. Analisis sifat alir serbuk (waktu alir dan sudut diam)
f. Uji pengetapan
g. Analisis kompaktibilitas
h. Analisis ukuran partikel

4. Analisis data yang diperoleh dari pengujian berbagai parameter tersebut dilakukan dengan cara deskriptif komparatif dimana data tersebut dibandingkan terhadap persyaratanpersyaratan yang ada dalam Farmakope Indonesia dan kepustakaan lainnya.

\section{HASIL DAN PEMBAHASAN}

Dalam pembuatan eksipien sediaan tablet, bahan baku yang digunakan adalah amilumubi jalaryang telah mengalami berbagai macam proses pengolahan sehingga akhirnya didapatkan amilum ubi jalar termodifikasi dalam bentuk serbuk kering. Berdasarkan hasil determinasi, diketahui bahwa tanaman ubi jalar yang digunakan dalam penelitian berasal dari famili Convolvulaceae dengan jenis spesies yaitu Ipomoea batatas Lamk.

\section{Pemeriksaan Kualitatif Amilum Ubi Jalar}

Amilum ubi jalar yang telah dibuat perlu dilakukan pemeriksaan secara kualitatif dengan tujuan untuk mengetahui kualitas amilum. Hasil uji kualitatif amilum ubi jalar alami dan modifikasi serta Amprotab dapat dilihat pada Tabel 1.

Tabel 1. Hasil uji kualitatif amilum ubi jalar dan Amprotab

\begin{tabular}{ccc}
$\mathbf{N}$ & Uji Kualitatif & $\begin{array}{c}\text { Amilum } \\
\text { Ubi } \\
\text { Jalar }\end{array}$ \\
\hline
\end{tabular}

1. Organoleptis (Bentuk, warna, bau, rasa)
a. Tanpa modifikasi
Putih
Putih
Serbuk Serbuk
b. Modifikasi dengan
pemanasan
Tidak Tidak
c. Modifikasi
berbau berbau
dengan pentanol-1
d. Modifikasi dengan proses asetilasi

\section{Kelarutan}
a. Tanpa modifikasi
Praktis
Praktis
b. Modifikasi
tidak tidak larut dengan larut dalam pemanasan dalam aquades
c. Modifikasi aquades dan etanol dengan dan pentanol-1
d. Modifikasi dengan proses asetilasi 
3. Identifikasi

lodium
a. Tanpa
Warna Warna biru modifikasi
ungu
b. Modifikasi
dengan pemanasan
c. Modifikasi
dengan
pentanol-1
d. Modifikasi
dengan
proses
asetilasi

4. Uji mikroskopik (bentuk dan hilus)
a. Tanpa modifikasi
Bentuk
bulat,
Bentuk
bulat, hilus
b. Modifikasi dengan pemanasa
hilus di
di tengah
c. Modifikasi
dengan
pentanol-1
d. Modifikasi
dengan
proses
asetilasi

seperti yang tercantum dalam

Farmakope Indonesia.

Amilum ubi jalar alami dan modifikasi serta Amprotab yang diberikan pelarut air menunjukkan bahwa kedua amilum tersebut tidak larut dalam air. Hal ini disebabkan karena kedua amilum lebih banyak mengandung amilopektin dibandingkan amilosa, dimana amilopektin tidak larut dalam air sedangkan amilosa dapat larut dalam air $^{[3]}$.

Amilum dengan dengan iodium akan membentuk kompleks amilumiod yang berwarna. Warna yang ditimbulkan dapat berbeda-beda tergantung perbedaan jumlah amilosa dan amilopektin. Amilosa dengan iodium akan berwarna biru kelam ${ }^{[4]}$. Pada pemeriksaan, amilum ubi jalar menghasilkan warna ungu dan Amprotab berwarna biru kelam, hal ini dikarenakan amilum ubi jalar lebih banyak mengandung amilopektin dibandingkan amilosa dan kandungan amilosa pada Amprotab lebih banyak dibanding amilum ubi jalar.

\section{Menurut}

Farmakope jenis amilum ubi jalar yang dibuat dan Amprotab mempunyai bentuk serbuk halus dan berwarna putih. Di samping itu, amilum juga tidak mempunyai rasa dan tidak berbau. Dengan demikian, amilum ubi jalar yang diuji telah memenuhi persyaratan organoleptis 
terdiri dari dua atau tiga butir tunggal yang tidak sama bentuknya. Bentuk partikel juga mempengaruhi densitas bulk dimana partikel-partikel dengan bentuk irregular cenderung memiliki porositas besar diakibatkan karena rongga antar partikel yang terisi oleh udara sehingga densitas bulk lebih kecil. Hasil pemeriksaan menyatakan bahwa semua jenis amilum ubi jalar dan amilum standar (Amprotab) memenuhi persyaratan uji mikroskopik (bentuk dan hilus).

\section{Pemeriksaan Sifat Fisik Serbuk}

Berdasarkan uji sifat fisisk serbuk, diperoleh hasil secara keseluruhan seperti pada Tabel 2.

Tabel 2. Hasil pemeriksaan sifat fisik amilum ubi jalar dan Amprotab

\begin{tabular}{|c|c|c|c|c|c|}
\hline $\begin{array}{c}\text { Jenis } \\
\text { Pemeriksaan }\end{array}$ & $\begin{array}{c}1 \\
(\bar{X} \pm S D)\end{array}$ & $\begin{array}{c}2 \\
(\bar{X} \pm S D)\end{array}$ & $\begin{array}{c}3 \\
(\bar{X} \pm S D)\end{array}$ & $\begin{array}{c}4 \\
(\bar{X} \pm S D)\end{array}$ & $\begin{array}{c}5 \\
(\bar{X} \pm S D)\end{array}$ \\
\hline Waktu alir & - & - & - & - & - \\
\hline Sudut diam & - & - & - & - & - \\
\hline Pengetapan & $15,4 \pm 2,41$ & $20,6 \pm 1,95$ & $21,6 \pm 1,52$ & $24,6 \pm 1,13$ & $28,0 \pm 1,58$ \\
\hline $\begin{array}{l}\text { Kompaktibilitas } \\
\text { Skala } \\
\text { kekerasan: } \\
5\end{array}$ & $\begin{array}{l}0,72 \pm 2,19 \\
\times 10^{-2}\end{array}$ & - & - & $\begin{array}{l}0,62 \pm 1,34 \\
\times 10^{-2}\end{array}$ & $\begin{array}{l}0,59 \pm 1,41 \\
\times 10^{-2}\end{array}$ \\
\hline 6 & $1,53 \pm 0,15$ & $\begin{array}{l}0,56 \pm 8,37 \\
\times 10^{-3}\end{array}$ & $\begin{array}{l}0,54 \pm 4,47 \\
\times 10^{-3}\end{array}$ & $\begin{array}{l}1,04 \pm 4,50 \\
\times 10^{-2}\end{array}$ & $\begin{array}{l}0,84 \pm 4,77 \\
\times 10^{-2}\end{array}$ \\
\hline 7 & $4,52 \pm 0,74$ & $1,00 \pm 0,08$ & $0,73 \pm 0,06$ & $2,55 \pm 0,34$ & $2,01 \pm 0,24$ \\
\hline Ukuran partikel & $18,25 \pm 2,69$ & $15,80 \pm 3,79$ & $14,55 \pm 1,76$ & $12,90 \pm 1,59$ & $15,20 \pm 1,79$ \\
\hline
\end{tabular}

Keterangan jenis amilum:

(1) Amprotab

(2) Amilum ubi jalar tanpa modifikasi

(3) Amilum modifikasi dengan panas langsung

(4) Amilum modifikasi dengan pentanol-1

(5) Amilum modifikasi dengan asam asetat

\section{a. Waktu Alir}

Waktu alir berperan penting dalam pengisisan granul ke dalam ruang kompresi yang nantinya akan menentukan keseragaman bobot tablet. Apabila serbuk atau granul mempunyai sifat alir yang baik maka pengisian pada ruang kompresiakan menjadi baik sehingga sediaan yang dihasilkan mempunyai bobot yang seragam ${ }^{[5]}$. Menurut Guyot, untuk 100 gram serbuk dengan waktu alir lebih dari 10 detik akan 
mengalami kesulitan dalam penabletan.

Tabel 3. Hasil pemeriksaan sudut diam dan waktu alir amilum ubi jalar dan Amprotab

\begin{tabular}{ccc}
$\begin{array}{c}\text { Jenis } \\
\text { amilum }\end{array}$ & $\begin{array}{c}\text { Waktu } \\
\text { (detik) }\end{array}$ & $\begin{array}{c}\text { Sudut } \\
\text { Diam }\left({ }^{\circ}\right)\end{array}$ \\
\hline 1 & - & - \\
2 & - & - \\
3 & - & - \\
4 & - & - \\
5 & - & -
\end{tabular}

Keterangan jenis amilum:

(1) Amprotab

(2) Amilum ubi jalar tanpa modifikasi

(3) Amilum modifikasi dengan panas langsung

(4) Amilum modifikasi dengan pentanol-1

(5) Amilum modifikasi dengan asam asetat

Pada Tabel 3, dapat dilihat bahwa amilum ubi jalar alami dan modifikasi serta Amprotab tidak memiliki waktu alir yang berarti amilum memiliki sifat alir tidak baik. Hal ini dikarenakan amilum ubi jalar mempunyai bentuk serbuk yang tidak seragam dan ukuran partikel yang kecil dan halus, sehingga akan memperbesar daya kohesinya serta memperlambat aliran serbuk.

\section{b. Sudut Diam}

Besar kecilnya sudut diam antara lain dipengaruhi oleh bentuk dan ukuran serbuk. Serbuk akan mengalir dengan baik jika memiliki sudut diam antara $25^{\circ}-45^{0[7]}$. Faktor yang memengaruhi sudut diam adalah gaya tarik dan gaya gesek antar partikel. Semakin kecil gaya tarik dan gesek antar partikelnya, maka semakin kecil sudut diamnya, dan demikian pula sebaliknya ${ }^{[8]}$. Beberapa kriteria sifat alir serbuk yang didasarkan sudut diamnya dapat dikelompokkan sebagai berikut:

Tabel 4. Kriteria sifat alir serbuk ${ }^{[9]}$

\begin{tabular}{cc}
\hline Sudut diam & Sifat alir \\
\hline$<25$ & Sangat baik \\
$25-30$ & Baik \\
$30-40$ & Sedang \\
$>40$ & Sangat jelek \\
\hline \multicolumn{2}{c}{ Pada semua jenis amilum ubi }
\end{tabular}
jalar yang dihasilkan serta Amprotab tidak memiliki sudut diam sehingga tidak memenuhi syarat sifat alir yang baik, dengan kata lain bahwa amilum tidak mengalir pada waktu dilakukan uji waktu alir, sehingga sudut diamnya pun tidak diperoleh.

\section{c. Pengetapan}

Besar kecil indeks pengetapan sangat ditentukan oleh kemampuan serbuk dalam mengisi ruang antar partikel dan memadat secara lebih rapat saat terjadi getaran volumenometer. Harga indeks pengetapan yang kecil menunjukkan bahwa serbuk dapat menata diri dengan baik sehingga pada pengetapan tidak memberikan penurunan volume yang besar.

Tabel 5. Hasil uji pengetapan amilum ubi jalar dan Amprotab (\%)

$\begin{array}{cc}\text { Jenis } & \text { Hasil rata-rata } \\ \text { amilum } & \text { pengetapan }(\bar{X} \pm S D)\end{array}$




\begin{tabular}{ll}
\hline 1 & $15,4 \pm 2,41$ \\
2 & $20,6 \pm 1,95$ \\
3 & $21,6 \pm 1,52$ \\
4 & $24,6 \pm 1,13$ \\
5 & $28,0 \pm 1,58$
\end{tabular}

Keterangan jenis amilum:
(1) Amprotab
(2) Amilum ubi jalar tanpa modifikasi
(3) Amilum modifikasi dengan panas langsung
(4) Amilum modifikasi dengan pentanol-1
(5) Amilum modifikasi dengan asam asetat

Semakin kecil indeks pengetapan (\%) maka semakin baik sifat alirnya. Serbuk dengan indeks pengetapan kurang dari $20 \%$ mempunyai sifat alir yang baik ${ }^{[6]}$. Berdasarkan hasil pemeriksaan uji pengetapan seperti yang tertera pada Tabel 5, didapatkan bahwa indeks pengetapan rata-rata semua amilum ubi jalar yang dibuat memiliki nilai lebih dari 20\%. Berbeda dengan Amprotab yang memiliki indeks pengetapan kurang dari $20 \%$. Hal ini menunjukkan bahwa amilum ubi jalar yang dihasilkan memiliki kompresibilitas yang tidak baik.

\section{d. Kompaktibilitas}

$$
\text { Uji kompaktibilitas }
$$

dimaksudkan untuk mengetahui kemampuan serbuk untuk saling berikatan menjadi massa yang kompak. Digunakan mesin tablet single punch dengan berbagai tekanan dari yang rendah ke yang tinggi. Kedalaman punch atas turun ke ruang die diatur sebesar $1 \mathrm{~cm}$ dengan diameter dies $13 \mathrm{~mm}$.

Tabel 6. Hasil uji kompaktibilitas amilum ubi jalar dan Amprotab (kg)

\begin{tabular}{|c|c|c|c|}
\hline \multirow[b]{3}{*}{$\begin{array}{c}\text { Jenis } \\
\text { amilum }\end{array}$} & \multicolumn{3}{|c|}{ Kekerasan } \\
\hline & 5 & 6 & 7 \\
\hline & $\begin{array}{c}\text { Rata-rata } \\
\text { kompak } \\
\text { tibilitas } \\
(\bar{X} \pm S D)\end{array}$ & $\begin{array}{c}\text { Rata-rata } \\
\text { kompak } \\
\text { tibilitas } \\
(\bar{X} \pm S D)\end{array}$ & $\begin{array}{c}\text { Rata-rata } \\
\text { kompak } \\
\text { tibilitas } \\
(\bar{X} \pm S D)\end{array}$ \\
\hline 1 & $\begin{array}{c}0,72 \pm \\
2,19 x \\
10^{-2}\end{array}$ & $\begin{array}{c}1,53 \pm \\
0,15\end{array}$ & $\begin{array}{c}4,52 \\
\pm 0,74\end{array}$ \\
\hline 2 & - & $\begin{array}{c}0,56 \pm \\
8,37 x \\
10^{-3}\end{array}$ & $\begin{array}{c}1,00 \pm 0,08 \\
0,73\end{array}$ \\
\hline 3 & - & $\begin{array}{c}0,54 \pm \\
4,47 x \\
10^{-3}\end{array}$ & $\pm 0,06$ \\
\hline 4 & $\begin{array}{c}0,62 \pm \\
1,34 x \\
10^{-2}\end{array}$ & $\begin{array}{c}1,04 \pm \\
4,50 x \\
10^{-2}\end{array}$ & $\pm 0,34$ \\
\hline 5 & $\begin{array}{c}0,59 \pm \\
1,41 x \\
10^{-2}\end{array}$ & $\begin{array}{c}0,84 \pm \\
4,77 x \\
10^{-2}\end{array}$ & $\pm 0,24$ \\
\hline
\end{tabular}

(1) Amprotab

(2) Amilum ubi jalar tanpa modifikasi

(3) Amilum modifikasi dengan panas langsung

(4) Amilum modifikasi dengan pentanol-1

(5) Amilum modifikasi dengan asam asetat

Pada

pemeriksaan kompaktibilitas, amilum ubi jalar dengan modifikasi menggunakan pentanol-1, asam asetat glasial, dan Amprotab dapat membentuk tablet pada skala kekerasan 5, 6, dan 7 . Untuk amilum ubi jalar alami dan amilum ubi jalar dengan modifikasi panas langsung hanya dapat membentuk tablet pada skala kekerasan 6 dan 7. Hal ini menunjukkan bahwa modifikasi amilum ubi jalar dengan menggunakan 
pentanol-1 dan asam asetat glasial menghasilkan amilum yang lebih bagus kompaktibilitasnya dibandingkan dengan amilum ubi jalar alami dan amilum ubi jalar dengan modifikasi panas langsung.

Ukuran partikel berpengaruh pada kompaktibilitas tablet saat pencetakan. Serbuk dengan ukuran partikel yang kecil dan halus dapat mengisi ruang cetakkan dengan baik $^{[10]}$. Dibandingkan dengan kedua modifikasi yang lain dan juga amilum ubi jalar alami, modifikasi dengan menggunakan pentanol-1 memiliki kompaktibilitas paling baik. Hal ini disebabkan karena ukuran partikel amilum yang dimodifikasi menggunakan pentanol-1 lebih kecil dibanding ketiga jenis amilum ubi jalar lainnya.

\section{KESIMPULAN}

1. Karakteristik fisikokimia amilum ubi jalar alami dan modifikasi mempunyai bentuk serbuk halus, berwarna putih, tidak berbau dan tidak berasa. Pada uji sifat alir dan sudut diam, serbuk amilum ubi jalar alami dan modifikasi tidak dapat mengalir sehingga tidak mempunyai sudut diam. Amilum ubi jalar alami dan modifikasi tidak larut dalam air dan etanol, pada tes iodine amilum ubi jalar memberikan warna ungu.

2. Kompaktibilitas amilum ubi jalar modifikasi dengan menggunakan pentanol-1 dan asam asetat glasial yang dapat dikempa pada skala kekerasan 5, 6, dan 7 lebih bagus jika dibandingkan dengan amilum ubi jalar alami dan amilum ubi jalar dengan modifikasi panas langsung yang hanya dapat dikempa pada skala kekerasan 6 dan 7. Amilum ubi jalar dengan modifikasi menggunakan pentanol-1 dan asam asetat glasial menghasilkan amilum yang kompaktibilitasnya setara dengan Amprotab karena ketiga jenis amilum ini sama-sama dapat dikempa pada skala kekerasan 5,6 , dan 7 .

\section{DAFTAR PUSTAKA}

[1] Fittasari, G., 2008, Karakterisasi Amilum Ubi Jalar (Ipomoea batatas L.) Sebagai Bahan Tambahan dalam Formulasi Sediaan Farmasi, Laporan Penelitian, Universitas Islam Indonesia, Yogyakarta.

[2] Syukri, Y dan Firdaus, F., 2009. Studi Potensi Berbagai Pati Tropis Dari Umbi-Umbian Lokal Indonesia Khususnya Ubi Kayu/Singkong (Manihot utilissima Pohl.) Dan Ubi Jalar (Ipomoea batatas L.) Sebagai Bahan Baku Pembuatan Eksipien Tablet, Laporan Penelitian Pendahuluan, Farmasi FMIPA UII, Yogyakarta.

[3] Bolhuis, G. K., 1998, Formulation and Disintegration Aspect of Tablet Prepared by Direct Compression and Wet Granulation, Laboratory for Pharmaceutical Technology and 
Dispensing University of Groningen, Groningen, The Nederland, 3-60.

[4] Winarno, F.G., 1986, Kimia Pangan dan Gizi, Edisi 2, Penerbit PT. Gramedia, Jakarta, 27-34.

[5] Parrott, E. L., 1971, Pharmaceutical Technology Fundamental Pharmaceutics, Edisi III, Burges Publishing Company, Mineapolis, 7386.

[6] Fudholi, A., 1983, Metodologi Formulasi dalam Kompresi Direct, Majalah Medika, 8, Gadjah Mada University, Yogyakarta, 586-593.

[7] Wadke, H. A., And Jacobson, H., 1980, Preformulation Testing in Lieberman, H. A., and Lachman, L., (editor), Pharmaceutical Dosage Forms: Tablets, Vol I, Marcel Dekker Inc, New York, 45.

[8] Fonner, D. E., Anderson, N. R., Banker, G. S, 1990, Granulation Technology and Tablet Caracterization in Lieberman, H. A., Lachman, L., Kanig, J. L., (editor), Pharmaceutical Dosage Forms : Tablets, Vol II, Marcel Dekker Inc., New York, 289-330.

[9] Sulaiman, T.N.S., 2007, Teknologi dan Formulasi Sediaan Tablet, Pustaka Laboratorium Teknologi Farmasi Fakultas Farmasi Universitas Gadjah Mada, Yogyakarta, 49-176.

[10] Lachman, L., Lieberman H. A., Kanig, J. L., 1994, Teori dan Praktek Farmasi Industri, diterjemahkan oleh Siti Suyatmi, Edisi III, Universitas
Indonesia, Jakarta, 1389, 1514, 1516, 1587, 1591, 1618. 